\title{
Implementation and use of standardized outcome measures by physical therapists in Saudi Arabia: barriers, facilitators and perceptions
}

\author{
Tahani N. Al-Muqiren', Einas S. Al-Eisa ${ }^{2}$, Ahmad H. Alghadir ${ }^{2}$ and Shahnawaz Anwer ${ }^{2,3^{*}}$ (D)
}

\begin{abstract}
Background: The use of standardized outcome measures (SOMs) has been recommended in the physical therapy practice guidelines to improve the patient's management and encourage the evidence based practice. However, the extent of the use of SOMs by physical therapists (PTs) in Saudi Arabia was not investigated. The present study aimed to (1) evaluate the extent of the use of SOMs by PTs in routine daily practice in Saudi Arabia; (2) explore the barriers, facilitators and perceptions in the use of SOMs during physical therapy services; (3) examine the relationship between facility settings and the PTs characteristics and the use of SOMs.

Methods: The present study used an observational design. A survey based questionnaire used and distributed to 352 PTs who were working in Saudi Arabia and was commonly involved in the management of patients within different clinical settings, either private or public.

Results: One-hundred-eighty participants completed the questionnaires (response rate of 51\%). One-hundred-eleven (62\%) participants indicated that they used SOMs in their practice. The most common barriers to using the SOMs were time-consuming for patients and therapist and difficult to understand the outcome measures by the patients. Those with a Masters degree were 3.5 times more likely to use SOMs compared to PTs with diploma level qualification [Odd Ratio $(95 \%$ Cl) $3.5(0.9-12.6)]$. Participants with a clinical specialty were nearly 3 times more likely to use SOMs than those who do not have a specialty [Odd Ratio (95\% Cl) 2.9 (1.6-5.5)].

Conclusions: Nearly two-thirds of the participants indicated that they used SOMs in clinical practice. Time-consuming for patient and therapist, difficult to understand the SOMs by the patients were the main perceived barriers. Years of experience, professional degree, and clinical specialty had a high probability of using SOMs. The majority of the participants showed the willingness to use SOMs in the future.
\end{abstract}

Keywords: Outcome, Standardized measure, Physical therapy, Rehabilitation, Barriers, Facilitators

\section{Background}

Standardized outcome measures (SOMs) are tools used for measuring the changes in the patients' performance, function or participation over time. The national health policy has strongly recommended the routine use of outcome [1]. Valid and reliable clinical outcome measurement can

\footnotetext{
* Correspondence: anwer_shahnawazphysio@rediffmail.com; anwerphysio@gmail.com

${ }^{2}$ Rehabilitation Research Chair, College of Applied Medical Sciences, King Saud University, Riyadh, Saudi Arabia

${ }^{3}$ Dr. D. Y. Patil College of Physiotherapy, Dr. D. Y. Patil Vidyapeeth, Pune, India Full list of author information is available at the end of the article
}

support better clinical decision-making, quality assurance and/or clinical research [2]. The SOMs have been used in the research setting to evaluate the effectiveness of treatment techniques [3]. In physical therapy, a good clinical practice pattern involves regular monitoring of the health status of patients using the SOMs [4]. In addition, SOMs can provide vital information for the therapists as well as patients, and help to improve the quality of patient management [5].

With an evolving trend in health care, a more patientfocused approach has been used for reducing disability 
and improving the quality of life (QOL) [6]. The use of SOMs in practice will motivate the patients and improve patients' performance in daily activities and life participation rather than traditionally measured impairments (e.g. range of motion, strength) [7].

Over the last 15-20 years, approaches in rehabilitation, in general, has been shifted from professional artistry to an evidence-based practice (EBP) [8]. The use of SOMs often has been recommended to promote EBP, as well as to improve clinical practice [9]. Along with EBP, the use of the standardized instruments for measuring patients' activity limitation and participation restriction have been advocated by rehabilitation professionals for many years [7]. However, the incorporation of routine outcome measurement in clinical practice has been neglected to a great extent [10]. The majority of allied health professionals had reported pragmatic barriers to using the outcome measures in clinical practice [1]. A variety of facilitators and barriers to routine use of outcome measurement by allied health professionals in clinical practice were identified [1]; four major themes were classified: knowledge, education, and perceived value in the outcome measurement; practical considerations; support/priority for outcome measure use; and the patient considerations.

In the last twenty years, the use of outcome measurement in daily practice has been strongly recommended in the allied health professions [11]. However, physical therapists (PTs) are still not willing to implement the use of SOMs routinely in most of the clinical settings [7]. A recent study examined the belief of Egyptians PTs in EBP and SOMs, the extent of their adoption in clinical practice, and the perceptions of EBP and SOMs benefits and barriers to their adoption [12]. Despite more than $90 \%$ of Egyptian PTs believing in EBP and SOMs, only approximately $49 \%$ of the PTs adopted EBP and 43\% adopted SOMs in clinical practice. Furthermore, in another study, approximately $90 \%$ of the participants reported that the use of SOMs improved communication between patients and therapists and it also helped to determine a plan of care [7]. However, there is a lack of information about the use of SOMs by PTs in Saudi Arabia. Moreover, no previous study had examined the current status, barriers and facilitators and perception to use SOMs by rehabilitation professionals in Saudi Arabia. Therefore, the present study intended to: (1) evaluate the extent of the use of SOMs by PTs in routine daily practice in Saudi Arabia; (2) explore the barriers, facilitators and perception in the use of SOMs during physical therapy services; and (3) examine the relationship between facility settings and the PTs characteristics and the use of SOMs.

\section{Methods}

\section{Participants}

The study sample comprised PTs who were working in Saudi Arabia and were commonly involved in the management of patients within different clinical setting either private or public. The PTs with an active license who were working in clinical setting were invited to participate. The PTs who were working outside of Saudi Arabia, undergraduate students, and PTs who were working in different sections like administration only or non-clinicians (not dealing with patients) were excluded from the study. The present study had ethical approval from the King Saud University Institutional Review Board (Postgraduate and Research Committee of Health Rehabilitation Sciences Department). An informed consent form was given to each potential participant to explain and obtain written acceptance. Confidentiality was maintained throughout the study.

\section{Procedures}

The present study used an observational design. Threehundred-fifty-two potential participants were selected from the list of PTs working in Saudi Arabia as provided by the Ministry of Health $(\mathrm{MOH})$. The sample size was calculated based on an estimated 50\% response rate with a 95\% confidence level and a confidence interval of three or less if a response was selected by $50 \%$ of the sample. The sample was randomly selected using computer generated process and three geographic regions including Makkah, Al-Madinah Almunawrah, and Eastern province was used for stratification of the sample from the hospital outside Riyadh and rural areas. Five major public hospitals and five private hospitals were also used for stratification of the sample in the Riyadh hospitals. Based on the numbers of PTs, 20 participants for each five main public hospitals and 10 participants for each five private hospitals in the Riyadh were invited. In addition, an email with the link to electronic Google drive survey software program for a web-based survey was sent randomly to 202 physical therapists working in the hospitals outside of Riyadh and rural areas. Each potential participant received a consent form and an explanation about the aim and significance of the study as well as an overview of the survey contents and lastly an appreciation for participating in the study. A reminder was sent to the participants after three weeks if the completed questionnaire was not returned. None of the authors were known to any of the participants. Participants were known by his/her email account.

The original English version of the survey instrument was used in this study [7]. Permission was taken from the original author to use their survey tool in this present study. Cronbach alpha was calculated to determine internal consistency for each of the factors. All 
items related to beliefs about the facilitators and the barriers to the use of standardized outcome measures was $\operatorname{good}(\alpha=0.84$ and $\alpha=0.83$, respectively).

\section{Statistical analysis}

The statistical software IBM SPSS (version 21 for Windows; IBM Inc., Chicago, IL, USA) was used to analyze the data. Means and response frequencies were presented. To investigate the association of participant characteristics, including gender, working experience, qualification, specialty, and facility setting with the use of SOMs, a multivariate logistic regression analysis was conducted. Odds ratios with 95\% confidence intervals were reported for each level of the independent variables. A reference group was selected for each variable for the correct interpretation of the results. A $p<0.05$ was selected as a level of significance in all statistical analyses.

\section{Results}

\section{Participants' characteristics}

From 352 invited participants, 183 responses were received (52\% response rate). Two participants were excluded from the analysis because the majority of their patients were outside of the Saudi Arabia, one questionnaire was returned with no responses. The remaining 180 questionnaires were included in the analysis representing an effective response rate of $51 \%$. The participants' characteristics are illustrated in Table 1. Fifty-eight percent of the participants were female. The majority of the samples were baccalaureate holders (75\%), and approximately 29\% of participants had 6-10 years of experience. Eighty-five percent of the participants had a professional degree, and the majority (79\%) was working in Riyadh. Thirty-two percent worked in an acute care setting. Approximately 52\% of the sample did not carry a specialty certification. Among those who were specialized, the majority were orthopedic or neurology specialty. On average, the PTs of this current sample treated 9 patients per day.

\section{Perceptions of standardized outcome measures Perception of benefits}

Of the 180 participants, 111 (62\%) indicated that they used SOMs in practice. Table 2 indicates the observed benefits of using SOMs in clinical practice in the participants who used SOMs. More than $70 \%$ of the participants who used SOMs agreed that SOMs enhanced communication between the therapist and patients, increased the efficiency of examinations, helped to motivate the choice of interventions, helped to motivate and encourage patients, and to attain better patients' outcomes.

\section{Barriers}

The most common barriers to using SOMs (as shown in Table 3) were too much time taken for the therapist to calculate and analyze scores, time-consuming for patients to complete it and difficulty in completing it independently, requiring too high a reading level for many patients, confusing to patients because of the English language used in which many of the patients are not fluent. Fifty-four percent of the participants who were using SOMs reported that the use of SOMs leads to confusion for the patients. More than half of participants who used SOMs disagreed that SOMs did not contain information that helped to direct the plan of care, and culture was not a concern of our participants.

\section{Implementation of SOMs in practice}

Approximately $60 \%$ of the participants who used SOMs reported the routine use of SOMs for examining and documenting the status, progress and/or outcomes of individual patients by an individual therapist, to communicate with the other healthcare providers, and quality improvement (as shown in Table 4).

Of the participants who used SOMs, 30\% responded that they were mandated for all their patients, while $24 \%$ of them reported it was mandated only for those patients who have particular types of disorders (e.g., low back pain) and $72 \%$ used information derived from patients' self-report. The most common way (61\%) of collecting the patient's data or analyzing the outcome was using paper followed by computer data entry by the therapists. Eighty percent of the participants used questionnaires that require patients' self-reports completed by patients themselves, and $67 \%$ used the same health status questionnaires in their setting. The majority of participants (66\%) learned how to use health status questionnaires either in professional or post- professional education level (as shown in Table 5).

Only 77 (69\%) participants answered the open questions and provided the list of SOMs they used in their practice; $43 \%$ of participants used Numerical Pain Rating Scale (NPRS) and Visual Analogue Scale (VAS), 35\% used Functional Independence Measure (FIM), and 31\% used Berg Balance Scale (BBS), 22\% used Fall Risk Inventory and Oswestry Low Back Pain Disability Index (OLDI), 17\% used 6-Minute walk test and Timed "Up \& Go" Test, $10 \%$ used 10-M gait speed, and 5\% used Rolland Morris Disability Index (RMDI) and Knee Osteoarthritis Outcome Scale (KOOS).

The most frequent reasons for choosing specific SOMs by the participants were if it was easy for the patients to understand and complete quickly. However, 50\% of the participants responded that they selected SOMs when it is valid and reliable, and easy to administer by the therapists (as shown in Table 6). 
Table 1 Participant characteristics $(N=180)$

\begin{tabular}{|c|c|c|c|}
\hline Variable & $\mathrm{N}$ & Percentage & $\begin{array}{l}\text { Percentage of } \\
\text { respondents } \\
\text { that uses outcome } \\
\text { measures }\end{array}$ \\
\hline \multicolumn{4}{|l|}{ Gender } \\
\hline Male & 75 & 41.7 & 64.0 \\
\hline Female & 105 & 58.3 & 60.0 \\
\hline \multicolumn{4}{|c|}{ Years of physical therapist practice } \\
\hline$<3$ years & 42 & 23.3 & 50.0 \\
\hline $3-5$ years & 27 & 15.0 & 74.1 \\
\hline $6-10$ years & 52 & 28.9 & 73.1 \\
\hline $11-20$ years & 41 & 22.8 & 60.0 \\
\hline$>20$ years & 18 & 10.0 & 39.0 \\
\hline \multicolumn{4}{|l|}{ Professional degree } \\
\hline Diploma & 21 & 11.7 & 23.8 \\
\hline Baccalaureate & 135 & 75.0 & 63.0 \\
\hline Master's & 24 & 13.3 & 85.7 \\
\hline \multicolumn{4}{|l|}{ Specialty certification } \\
\hline None & 94 & 52.2 & 74.4 \\
\hline Orthopedic & 32 & 17.8 & \\
\hline Neurology & 18 & 10.0 & \\
\hline Pediatric & 6 & 3.3 & \\
\hline Manual therapy & 17 & 9.4 & \\
\hline Hand therapy & 3 & 1.7 & \\
\hline Sports & 2 & 1.1 & \\
\hline Cardiovascular & 2 & 1.1 & \\
\hline Geriatric & 1 & 0.6 & \\
\hline Other & 5 & 2.8 & \\
\hline Type of work facility & $(1 \mathrm{~m}$ & & \\
\hline Acute care & 58 & 32.4 & 74.1 \\
\hline Sub-acute care & 37 & 20.7 & 73.0 \\
\hline Extended care & 37 & 20.7 & 43.2 \\
\hline Outpatient clinic & 31 & 17.3 & 45.2 \\
\hline Private clinic & 13 & 7.3 & 53.8 \\
\hline University & 3 & 1.3 & 74.1 \\
\hline \multicolumn{4}{|c|}{ Use of standardized outcome measure } \\
\hline Yes & 111 & 61.7 & \\
\hline No & 69 & 38.3 & \\
\hline \multicolumn{4}{|l|}{ Region } \\
\hline Riyadh & 142 & 79.0 & \\
\hline Makkah & 25 & 14.0 & \\
\hline $\begin{array}{l}\text { Al Madinah } \\
\text { Almunawrah }\end{array}$ & 5 & 3.0 & \\
\hline Eastern province & 8 & 4.4 & \\
\hline
\end{tabular}

Table 1 Participant characteristics ( $N=180)$ (Continued)

\begin{tabular}{|c|c|c|c|}
\hline Variable & $\mathrm{N}$ & Percentage & $\begin{array}{l}\text { Percentage of } \\
\text { respondents } \\
\text { that uses outcome } \\
\text { measures }\end{array}$ \\
\hline Treat all patients & 25 & 13.9 & \\
\hline$<21$ years & 19 & 10.6 & \\
\hline $21-40$ years & 45 & 25.0 & \\
\hline $41-60$ years & 72 & 40.0 & \\
\hline $61-75$ years & 18 & 10.0 & \\
\hline$>75$ years & 1 & 0.6 & \\
\hline \multicolumn{4}{|l|}{ Conditions } \\
\hline Musculoskeletal & 158 & 56.7 & \\
\hline Neurology & 132 & 32.8 & \\
\hline $\begin{array}{l}\text { Cardiovascular- } \\
\text { pulmonary }\end{array}$ & 60 & 6.4 & \\
\hline Women's health & 17 & 2.6 & \\
\hline Mixed & 97 & 11.0 & \\
\hline Integumentary & 22 & 2.4 & \\
\hline \multirow{2}{*}{$\begin{array}{l}\text { Do not manage } \\
\text { patients }\end{array}$} & 2 & 0.2 & \\
\hline & & $\bar{x}$ & \\
\hline $\begin{array}{l}\text { Treatment sessions } \\
\text { per 8-h day }\end{array}$ & & 9.3 & \\
\hline
\end{tabular}

\section{Reasons for not using SOMs}

Thirty-eight percent of participants indicated that they did not use SOMs in practice, with $14 \%$ indicating that they did not plan to use it in the future, while $86 \%$ reporting willingness to use SOMs in the future. The most frequent reasons for not using SOMs selected by the participants were time-consuming for the patients completing it, as well as for the therapists to analyze or calculate the score, and difficulty for the patients to complete independently. Thirty-five percent of the participants who did not use SOMs reported that the use of SOMs required specific training for improved usage, $38 \%$ responded that they believed the usefulness of SOMs is for research purposes only (as shown in Table 7).

\section{Participant characteristics influencing the use of standardized outcome measures}

Gender of participants had no relationship with using SOMs, while years of experience, professional degree, and clinical specialty had a high probability of using SOMs. The experience of participants was related to the likelihood of using SOMs. Compared with PTs who have had experience of 3 years or less, participants with experience of 6-10 years were 2.7 times more likely to use SOMs. The professional degree of participants was related to the likelihood of using SOMs. Compared with 
Table 2 Perceived Benefits among PTs who used Standard Outcome Measures (SOMs) $(n=111)$

\begin{tabular}{|c|c|c|c|c|c|c|}
\hline \multirow[t]{2}{*}{ Benefits } & \multicolumn{2}{|c|}{ Agree } & \multicolumn{2}{|c|}{ Agree somewhat } & \multicolumn{2}{|c|}{ Disagree } \\
\hline & $\mathrm{N}$ & Percent & $\mathrm{N}$ & Percent & $\mathrm{N}$ & Percent \\
\hline "Helping to direct the plan of care". & 75 & 67.6 & 35 & 31.5 & 1 & 0.9 \\
\hline "Enhancing communication between therapist and patient". & 81 & 72.9 & 30 & 27.1 & 0 & 0 \\
\hline "Enhancing communication with third-party payers, physicians, and other providers". & 64 & 57.7 & 42 & 37.8 & 5 & 4.5 \\
\hline "Helping patients feel that therapists are thorough in their examination". & 74 & 66.7 & 46 & 41.4 & 1 & 0.9 \\
\hline "Increasing the efficiency of examinations". & 82 & 73.9 & 27 & 24.3 & 2 & 1.8 \\
\hline "Helping to focus choice of interventions". & 83 & 74.8 & 28 & 25.2 & 0 & 0 \\
\hline "Attaining better patient outcomes". & 79 & 71.2 & 32 & 28.8 & 0 & 0 \\
\hline "Helping to motivate and encourage patients". & 81 & 72.9 & 30 & 27.1 & 0 & 0 \\
\hline "Decreasing the rates of denial from third-party payers". & 47 & 42.3 & 56 & 50.5 & 8 & 7.2 \\
\hline "Enhanced marketing of my practice or services". & 56 & 50.5 & 40 & 36.1 & 15 & 13.5 \\
\hline
\end{tabular}

the baccalaureate degree holder, Master's degree holder was 3.5 times more likely to use SOMs and the PTs with diploma qualification were less likely to use SOMs. Participants with a clinical specialty were 2.9 times more likely to use SOMs than those who do not have a specialty. The type of facility in which the participants practiced showed extended care and outpatient clinics were less likely to use SOMs than acute care [Odd Ratio (95\% CI) $0.3(0.1-0.7)]$ (as shown in Table 8).

\section{Discussion}

The majority of respondents in the present study were from Riyadh - capital city of Saudi Arabia which contains the larger main general, specialized, government and private hospitals than those in other cities. The result showed that $62 \%$ of the PTs of this sample were using SOMs in their clinical practice, consistent with previous studies $[2,7,13]$. In the Netherlands, Swinkle et al. [14] reported that $70 \%$ of respondent used at least one SOM in their daily practice. In Egypt, Elsobkey et al. [12] reported that $43 \%$ of respondents incorporate SOMs in their clinical practice, whilst Jett et al. [7] reported that $48 \%$ of responding members of the American Physical Therapy Association used SOMs. Another study reported that $53 \%$ of respondents from the Dutch physical therapy population used three of the seven recommended outcome measures as per the recommended clinical practice guidelines in the management of

Table 3 Perceived barriers among PTs who used Standard Outcome Measures (SOMs) $(n=111)$

\begin{tabular}{|c|c|c|c|c|c|c|}
\hline \multirow[t]{2}{*}{ Barriers } & \multicolumn{2}{|c|}{ Agree } & \multicolumn{2}{|c|}{$\begin{array}{l}\text { Agree } \\
\text { somewhat }\end{array}$} & \multicolumn{2}{|c|}{ Disagree } \\
\hline & $\mathrm{N}$ & Percent & $\mathrm{N}$ & Percent & $\mathrm{N}$ & Percent \\
\hline "Confusing to patients". & 35 & 31.3 & 55 & 49.1 & 21 & 18.9 \\
\hline "Difficult for patients to complete independently". & 42 & 37.8 & 58 & 52.3 & 11 & 9.9 \\
\hline "Require too high a reading level for many patients". & 39 & 35.1 & 59 & 53.2 & 13 & 11.7 \\
\hline "English language in which many of my patients are not fluent". & 59 & 53.2 & 35 & 31.5 & 17 & 15.3 \\
\hline "Not sensitive to the cultural/ethnic concerns of many patients". & 32 & 28.8 & 53 & 47.7 & 26 & 23.4 \\
\hline "Make patients anxious". & 8 & 7.2 & 52 & 46.8 & 51 & 45.9 \\
\hline "Take too much time for patients to complete". & 53 & 47.7 & 47 & 42.3 & 11 & 9.9 \\
\hline "Take too much of clinicians' time to analyze/calculate/score". & 48 & 43.2 & 44 & 39.6 & 19 & 17.1 \\
\hline "Provide information that is too subjective to be useful". & 21 & 18.9 & 59 & 53.2 & 31 & 27.9 \\
\hline "Require more effort than they are worth". & 20 & 18.1 & 50 & 45.1 & 41 & 36.9 \\
\hline "Do not contain information that helps to direct the plan of care". & 13 & 11.7 & 41 & 36.9 & 57 & 51.4 \\
\hline $\begin{array}{l}\text { "Difficult to interpret (eg, do not know what norms are, how score relates to severity, or what a clinically } \\
\text { important change might be)". }\end{array}$ & 14 & 12.6 & 53 & 47.7 & 44 & 39.6 \\
\hline "Do not contain the types of items or questions that are relevant for the type of patients I see". & 15 & 13.5 & 57 & 51.4 & 39 & 35.1 \\
\hline $\begin{array}{l}\text { "Often do not get completed at discharge, so cannot give information about patients response to } \\
\text { treatment". }\end{array}$ & 25 & 22.5 & 56 & 50.5 & 30 & 27.1 \\
\hline
\end{tabular}


Table 4 Uses of Information among PTs who used Standard Outcome Measures (SOMs) ( $\mathrm{n}=111)$

\begin{tabular}{|c|c|c|c|c|c|c|}
\hline \multirow[t]{2}{*}{ Health status Questionnaires used for } & \multicolumn{2}{|c|}{$\begin{array}{l}\text { Yes } \\
\text { Routinely }\end{array}$} & \multicolumn{2}{|c|}{$\begin{array}{l}\text { Yes } \\
\text { Sometime }\end{array}$} & \multicolumn{2}{|l|}{ No } \\
\hline & $\mathrm{N}$ & Percent & $\mathrm{N}$ & Percent & $\mathrm{N}$ & Percent \\
\hline "Answering clinical questions through a traditional research approach". & 45 & 40.5 & 62 & 55.9 & 4 & 3.6 \\
\hline "Quality improvement / assurance activities". & 59 & 53.2 & 48 & 43.2 & 4 & 3.6 \\
\hline "Determining the case mix (complexity) of patients". & 34 & 30.6 & 66 & 59.5 & 11 & 9.9 \\
\hline "Comparing performance across therapists in terms of average patient outcomes". & 49 & 44.1 & 50 & 45.1 & 12 & 10.8 \\
\hline "Comparing one clinic's performance to that of other clinics". & 41 & 36.9 & 49 & 44.1 & 21 & 18.9 \\
\hline "Comparing average outcomes of patients with different conditions within a practice". & 45 & 40.5 & 58 & 52.3 & 8 & 7.2 \\
\hline $\begin{array}{l}\text { "Examining the average change in patients' health status over their episodes of care to determine a } \\
\text { practice's effectiveness". }\end{array}$ & 62 & 55.9 & 45 & 40.5 & 4 & 3.6 \\
\hline $\begin{array}{l}\text { "Examining the average change in patients' health status over their episodes of care to determine individual } \\
\text { therapists' effectiveness". }\end{array}$ & 55 & 49.5 & 48 & 43.2 & 8 & 7.2 \\
\hline $\begin{array}{l}\text { "Examining and documenting the status, progress, and/or outcomes of individual patients by individual } \\
\text { therapists". }\end{array}$ & 63 & 56.8 & 48 & 43.2 & 0 & 0 \\
\hline "Communicating with other health care providers and referral sources". & 59 & 53.2 & 44 & 39.6 & 8 & 7.20 \\
\hline
\end{tabular}

patient with a stroke [13]. In addition, Copland et al. [15] reported that $40 \%$ of their New Zealand respondents used back pain outcome measures.

In the present study, it was found that PTs with experiences of more than 20 years were less likely to use SOMs than younger PTs. However, the difference was not statistically significant, although PTs with experiences of 6-10 years were more likely to use SOMs. This may reflect that there were few educational workshops, professional development courses in the past compared to present and more attention paid to the concern about the use of the SOM in contemporary entry level programs. Further, Swinkel et al. [14] found that younger PTs were more likely to use outcome measures, while conversely Jette et al. [7] found participants who had been practicing for more than 20 years were much more likely to use SOMs than younger colleagues.

In the present study, the participants who had a clinical specialization showed a higher percentage of SOMs usage $(74 \%)$ compared to non-specialized ones and most of them were in orthopedic or neurological settings. Abrams et al. [16] reported a 66\% use of SOMs amongst PTs who treat a majority of patients with orthopedic conditions. This is consistent with $91 \%$ of PTs with a neurology specialty in UK reporting use of SOMs in their practice [17].

Consistent with the study of Copeland et al. [15], in this present study participants having a Master's degree level qualification were much more likely to use SOMs in their clinical practice. In contrast, Elsobkey et al. [12] reported that the highest professional degree achieved by their respondents had no significant impact on whether SOMs were adopted or not.

Participants were requested to list the SOMs that they frequently used in their clinical practices. In line with the previous studies of Macdermid et al. [2] and Chapman et al. [18], the most frequently listed measures reported in this present study were NPRS and the VAS for pain assessment, and OLDI for low back pain.

It was not surprising to find that the use of SOMs in private clinics was lower than other clinical settings in the present study. However, the difference was statistically not significant. The less use of SOMs in the private clinics may be due to the insurance services in Saudi Arabia not considering the use of SOMs as one of the mandatory elements in the physical therapy assessment protocol to get physical therapy services. In addition, time prioritization in private clinics may be a factor as PTs need more time to use SOMs with their patient which may interfere with efficient patient flow. Furthermore, MacDiarmid et al. [2] found that the salaried clinicians used outcome measures more than counterparts. Vanpeppen et al. [13] reported that the PTs who were working in private physical therapy practices, showed poor adherence to clinical practice guidelines on the physical therapy management of patients with stroke. Moreover, Swinkels et al. [14] reported that the PTs in private clinics used SOMs less than nursing home PTs. Similarly, the present study showed a low percentage of SOMs used by respondents in both extended care and outpatient clinic settings, which may reflect timeconstraints, since these clinics are very busy with high numbers of patients which limit the amount of time available for each patient.

In the present study, $38 \%$ of respondents did not use SOMs but most of them indicated that they intended to use SOMs in the future. The majority of participants had a positive attitude towards the use of SOMs and they agreed about the advantages of SOMs. However, PTs indicated having barriers and facilitators during 
Table 5 Organization in clinical setting

\begin{tabular}{|c|c|c|}
\hline & N & Percent \\
\hline \multicolumn{3}{|l|}{ "In my practice setting, completion of health status questionnaires is", } \\
\hline "Mandated/required for all patients". & 34 & 30.3 \\
\hline "Mandated only for patients who have certain types of conditions (eg, low back pain)". & 27 & 24.1 \\
\hline "Routine for all patients/clients, but not mandated/required". & 11 & 9.8 \\
\hline "Routine, but not mandated, only for patients who have certain types of conditions (eg, low back pain)". & 18 & 16.1 \\
\hline "Sporadic, depending on different factors such as time, patient's characteristics, etc". & 22 & 19.6 \\
\hline \multicolumn{3}{|l|}{ "In my practice setting, the types of health status questionnaires used include", } \\
\hline "Only those that use information derived from patients' self-report". & 80 & 72.1 \\
\hline "Only those that use information derived from observation of patients' performance". & 14 & 12.6 \\
\hline "A combination of those that use patient/client self-report and observation of their performance". & 17 & 15.3 \\
\hline \multicolumn{3}{|l|}{ "In my practice setting, health status questionnaires are completed", } \\
\hline "Using paper and therapists review the raw information from the paper version". & 26 & 23.4 \\
\hline $\begin{array}{l}\text { "Using paper, analyzed/scored through scanner or computer data entry, and then summary scores } \\
\text { are reviewed by therapists". }\end{array}$ & 68 & 61.3 \\
\hline "Using the computer (no paper), and summary scores are reviewed by therapists". & 16 & 14.4 \\
\hline Other & 1 & 0.9 \\
\hline \multicolumn{3}{|l|}{ "In my practice setting, when I use questionnaires that require patients self-reports", } \\
\hline "Patients complete the health status questionnaires by themselves". & 76 & 67.9 \\
\hline "Office staff or aides assist patients/clients in completing health status questionnaires". & 25 & 22.3 \\
\hline "Physical therapists complete health status questionnaires with the patients". & 10 & 8.9 \\
\hline Other & 1 & 0.9 \\
\hline \multicolumn{3}{|l|}{ "Each physical therapist in my practice setting"; } \\
\hline "Uses the same health status questionnaires". & 75 & 67.0 \\
\hline "Chooses the health status questionnaires he or she wants to use for each patient". & 37 & 33.0 \\
\hline \multicolumn{3}{|l|}{ "I learned how to use health status questionnaires", } \\
\hline "In my professional (entry-level) program". & 38 & 34.2 \\
\hline "In my post-professional education". & 35 & 31.5 \\
\hline "From continuing education workshops/conferences". & 27 & 24.3 \\
\hline "From the other therapists or managers in my practice setting". & 11 & 9.9 \\
\hline
\end{tabular}

Table 6 The reasons for selecting Standard Outcome Measures (SOMs)

\begin{tabular}{|c|c|c|}
\hline Reasons & $\mathrm{N}$ & Percentage \\
\hline "Can be completed quickly". & 68 & 61.3 \\
\hline "Easy for patients to understand". & 75 & 67.6 \\
\hline "Easy for clinicians to understand/interpret meaning of scores and change in scores". & 49 & 44.1 \\
\hline "Shown to be valid and reliable". & 56 & 50.5 \\
\hline "Seem to be the most common ones used in physical therapist practice". & 38 & 34.2 \\
\hline "Useful for a variety of purposes such as research, quality assurance, patient/client evaluation". & 27 & 24.3 \\
\hline "Can be analyzed electronically (scanner, computer, etc.)". & 18 & 16.2 \\
\hline "Most appropriate for the types of conditions seen in my practice setting". & 35 & 31.5 \\
\hline "Other reason" & 1 & 0.90 \\
\hline "Do not know" & 2 & 1.80 \\
\hline
\end{tabular}


Table 7 Reasons among Participants who did not use Standard Outcome Measures (SOMs) $(n=69)$

\begin{tabular}{|c|c|c|}
\hline Reasons & $\mathrm{N}$ & Percentage \\
\hline "Confusing to patients". & 30 & 43.4 \\
\hline "Difficult for patients to complete independently". & 49 & 71.0 \\
\hline "Require too high a reading level for many patients". & 29 & 42.0 \\
\hline "English language in which many of my patients are not fluent". & 30 & 43.4 \\
\hline "Not sensitive to the cultural/ethnic concerns of many patients". & 11 & 15.9 \\
\hline "Make patients anxious". & 8 & 11.5 \\
\hline "Take too much time for patients to complete". & 52 & 75.7 \\
\hline "Take too much of clinicians' time to analyze/calculate/score". & 35 & 50.7 \\
\hline "Provide information that is too subjective to be useful". & 16 & 23.2 \\
\hline "Require more effort than they are worth". & 17 & 24.6 \\
\hline "Do not contain information that helps to direct the plan of care". & 15 & 21.7 \\
\hline $\begin{array}{l}\text { "Difficult to interpret (eg, do not know what norms are, how score relates to severity, or what a clinically } \\
\text { important change might be)". }\end{array}$ & 11 & 15.9 \\
\hline "Do not contain the types of items or questions that are relevant for the types of patients I see". & 8 & 11.5 \\
\hline "Often do not get completed at discharge, so are not useful for determining patients' response to treatment". & 12 & 17.4 \\
\hline "Require training that I do not have". & 24 & 34.8 \\
\hline "Cost too much". & 6 & 8.8 \\
\hline "Require a support structure that I do not have (eg, technology, staffing)". & 14 & 20.3 \\
\hline "Really only useful for research purposes". & 26 & 37.7 \\
\hline "Not relevant because my practice involves consultation, case management, or discharge planning only". & 8 & 11.5 \\
\hline \multicolumn{3}{|l|}{ Plan to implement? } \\
\hline Yes & 24 & 34.8 \\
\hline No & 10 & 14.5 \\
\hline Maybe & 35 & 50.7 \\
\hline
\end{tabular}

${ }^{\text {a }}$ May indicated more than one reason

their daily practice similar to what have been discussed in the literature $[1,7,12-15]$. The most important barriers perceived by the PTs who used SOMs and reasons for not using SOMs detected among participants was practical considerations, including time-consuming for both patients and the clinicians to complete the SOMs. Similarly, lack of time has been cited as the most frequent barrier selected by PTs in the previous studies $[1,7,14-16,19]$. In addition, the other notable barrier was an inability of patients to complete SOMs independently, which was consistent with Jett et al. [7] and Simmon et al. [20]. In other professions, such as occupational therapy and speech and language therapy, the same types of barriers as those reported by the PTs are evident [1]. The English language was a major barrier of the current sample faced with their patients, especially that some SOMs are not translated to Arabic "mother language". Similarly, Jett et al. [7] have reported language barriers for patients not fluent in English.

The opinion that the SOMs could support patients' communication to increase the efficiency of examination and treatment, to attain better patients' outcome and to motivate patients, were similar to the results of previous studies $[1,7,14,21]$. The high clinicians' perceived value of SOMs can increase the likelihood of their use in practice, whilst the lack of perceived value decreases uptake [1]. The results of the present study indicated that the most frequent use of information selected by participants were routine use of SOMs in assessing the patients status, improvement, average change in patients' health status over time to determine a practice's effectiveness, as well as to determine therapists' effectiveness, to improve communication with health care providers and to improve quality of patients' services. These reflect the participant's high perceived value of SOMs use.

Percentage of participants who use SOMs during clinical practice was fairly acceptable because almost half of the current sample considered the use of SOMs mandated by roles of hospitals either for all patients or certain types of condition. High level of organizational commitment and facility support could facilitate increased routine use of SOMs.

In the present study, the majority of participants have learned how to use SOMs in their professional education 
Table 8 Odds of Using Standard Outcome Measures (SOMs) by Participant and Practice Characteristics

\begin{tabular}{|c|c|c|c|c|}
\hline \multirow[t]{2}{*}{ Factors } & \multirow{2}{*}{$\begin{array}{l}\text { Odd } \\
\text { Ratio }\end{array}$} & \multirow[t]{2}{*}{ P-value } & \multicolumn{2}{|l|}{$95 \% \mathrm{Cl}$} \\
\hline & & & Lower & upper \\
\hline \multicolumn{5}{|l|}{ Gender } \\
\hline Male & Reference & 0.6 & & \\
\hline Female & 0.8 & & 0.5 & 1.6 \\
\hline \multicolumn{5}{|l|}{ Years of experience } \\
\hline$<3$ years & Reference & & & \\
\hline $3-5$ years & 2.9 & 0.05 & 0.9 & 8.2 \\
\hline $6-10$ years & 2.7 & 0.02 & 1.2 & 6.4 \\
\hline $11-20$ years & 1.6 & 0.32 & 0.7 & 3.7 \\
\hline$>20$ years & 0.6 & 0.43 & 0.2 & 1.9 \\
\hline \multicolumn{5}{|l|}{ Professional degree } \\
\hline Baccalaureate & Reference & & & \\
\hline Diploma & 0.2 & 0.002 & 0.1 & 0.5 \\
\hline Master's & 3.5 & 0.001 & 0.9 & 12.6 \\
\hline \multicolumn{5}{|l|}{ Facility } \\
\hline Acute care & Reference & & & \\
\hline Sub-acute care & 0.9 & 0.90 & 0.4 & 2.4 \\
\hline Extended care & 0.3 & 0.003 & 0.1 & 0.6 \\
\hline Outpatient clinic & 0.3 & 0.008 & 0.1 & 0.7 \\
\hline Private clinic & 0.4 & 0.16 & 0.1 & 1.4 \\
\hline \multicolumn{5}{|l|}{ Specialty } \\
\hline No & Reference & 0.001 & & \\
\hline Yes & 2.9 & & 1.6 & 5.5 \\
\hline
\end{tabular}

training; because of this, it is suggested that the education providers put more focus and attention on the use of SOMs in entry-level PT programs to facilitate the routine use of SOMs in clinical practice. In addition, SOMs were viewed to be more favorable to the participants if it is easy for patients to understand, to complete it quickly and independently, easy to interpret it and should be valid and reliable. Furthermore, it is recommended to make some following changes in the organization policy in different areas to promote the use of SOMs in Saudi Arabia. First, the use of SOMs made as the mandatory elements during the assessment and treatment of patients, via policy and procedures. Second, information about SOMs should be available in the professional journals, newsletters, and guidelines. Third, technical support, training, and access to software, and how to use and interpret the results of the SOMs in daily practice should be provided. Fourth, an educational opportunity should be available for PTs to increase their knowledge and skills about the use of SOMs during entry-level training and induce some of the changes in professional behavior. Finally, allocation of more time for each session to allow patient and therapist to obtain more opportunity to integrate the use of SOMs in clinical practice.

\section{Limitations}

The present study had some potential limitations. The present sample cannot be generalized about the total population in Saudi Arabia because the majority of them were in Riyadh city, it would not be representative enough. The results of the present study based on the participant 'self-report data that sometimes differ from reality. In addition, using two different ways for data collection, because the electronic survey had lower responses which forced us to use another way for more participants' recruitment, may reduce the validity of the results.

\section{Conclusions}

Standardized outcome measures are important tools that can provide valuable information for the patient and therapist, and help guide patient management. Nearly two-third of the participants indicated that they used SOMs in their practice. Most of them perceived that their uses enhanced examination and documentation of patient progression, determination of practice's effectiveness, communication with the patient and quality improvement. While, time-consuming for the patient and therapist, confusing and difficult to understand the SOMs were the main perceived barriers. There was a relationship between therapist characteristics and practice settings and the likelihood of using SOMs.

\section{Abbreviations}

BBS: Berg Balance Scale; FIM: Functional Independence Measure; KOOS: Knee Osteoarthritis Outcome Scale; NPRS: Numerical Pain Rating Scale;

OLDI: Oswestry Low Back Pain Disability Index; PTs: Physical Therapists; RMDI: Rolland Morris Disability Index; SOMs: Standardized Outcome Measures; VAS: Visual Analogue Scale

\section{Acknowledgments}

The authors are grateful to the Deanship of Scientific Research, King Saud University for funding through Vice Deanship of Scientific Research Chairs.

\section{Funding}

This project was funded by the Deanship of Scientific Research, King Saud University through Vice Deanship of Scientific Research Chairs. The funding body played no role on study design, the writing of the manuscript or the decision to submit the manuscript for publication.

Availability of data and materials

All data generated or analyzed during this study are presented in the manuscript. Please contact the corresponding author for access to data presented in this study.

\section{Authors' contributions}

SA: Corresponding author, participated in the design of the study, participated in the statistical analysis, drafted the manuscript and finished the manuscript. AA: participated in the design of the study, helped in ethics applications and revised the manuscript critically. TA: participated in the design of the study, developed the protocol, participated in the data collection, and revised the manuscript critically. EA: participated in the 
design of the study and revised the manuscript critically. All authors read and approved the final manuscript.

\section{Ethics approval and consent to participate}

The present study had an approval from the King Saud University Institutional Review Board (Postgraduate and Research Committee of Health Rehabilitation Sciences Department). An informed consent form was given to each participant to explain and obtain acceptance from each participant. Confidentiality was maintained throughout the study.

\section{Consent for publication}

Not Applicable.

\section{Competing interests}

The authors declare that they have no competing interests.

\section{Publisher's Note}

Springer Nature remains neutral with regard to jurisdictional claims in published maps and institutional affiliations.

\section{Author details}

${ }^{1}$ King Abdulaziz Medical City, Riyadh, Saudi Arabia. ${ }^{2}$ Rehabilitation Research Chair, College of Applied Medical Sciences, King Saud University, Riyadh, Saudi Arabia. ${ }^{3}$ Dr. D. Y. Patil College of Physiotherapy, Dr. D. Y. Patil Vidyapeeth, Pune, India.

Received: 25 January 2017 Accepted: 7 November 2017

Published online: 21 November 2017

\section{References}

1. Duncan EA, Murray J. The barriers and facilitators to routine outcome measurement by allied health professionals in practice: a systematic review. BMC Health Serv Res. 2012;12:96. https://doi.org/10.1186/1472-6963-12-96.

2. Macdermid JC, Walton DM, Côté P, Santaguida PL, Gross A, Carlesso L. ICON Use of outcome measures in managing neck pain: an international multidisciplinary survey. Open Orthop J. 2013;7:506-20. https://doi.org/10. 2174/1874325001307010506. eCollection 2013

3. Beattle P. Measurement of health outcomes in the clinical sitting: application to physiotherapy. Physiother Theory Pract. 2001;17:173-85.

4. Glasziou P, Irwig L, Mant D. Monitoring in chronic disease: a rational approach. BMJ. 2005:330(7492):644-8.

5. Hefford C, Abbott JH, Baxter GD, Arnold R. Outcome measurement in clinical practice: practical and theoretical issues for health related quality of life (HRQOL) questionnaires. Phys Ther Rev. 2011;16:155-67. https://doi.org/ 10.1179/1743288X11Y.0000000004.

6. Mulroy SJ, Winstein CJ, Kulig K, Beneck GJ, Fowler EG, DeMuth SK, et al. Secondary mediation and regression analyses of the PTClinResNet database: determining causal relationships among the international classification of functioning, disability and health levels for four physical therapy intervention trials. Phys Ther. 2011;91(12):1766-79. https://doi.org/10.2522/ ptj.20110024.

7. Jette DU, Halbert J, Iverson C, Miceli E, Shah P. Use of standardized outcome measures in physical therapist practice: perceptions and applications. Phys Ther. 2009;89(2):125-35. https://doi.org/10.2522/ptj. 20080234

8. Richardson D. Physical therapy in spasticity. Eur J Neurol. 2002;9(Suppl 1):17-22.

9. Tyson S, Watson A, Moss S, Troop H, Dean-Lofthouse G, Jorritsma S, et al. Development of a framework for the evidence- based choice of the outcome measure in neurological physiotherapy. Disabil Rehabil. 2008:30(2):142-9.

10. Unsworth CA. Evidence-based practice depends on the routine use of outcome measures (Editorial). Br J Occup Ther. 2011;74(5):209. https://doi. org/10.4276/030802211X13046730116371.

11. Ellwood P. Outcomes management - a technology of patient experience. N Engl J Med. 1988:318:1549-56.

12. El-Sobkey SB, Helmy AM. Evidence-based practice and standardized outcome measures: Egyptian physical therapists' beliefs, perceptions and adoption. World Appl Sci J. 2012;16(9):1282-91

13. Van Peppen RPS, Maissan FJF, van Genderen FR, van Dolder E, Meeteren NLU. Outcome measures in physiotherapy management of patients with stroke: a survey into self-reported use, and barriers to and facilitators for use. Physiother Res Int. 2008;13(4):255-70. https://doi.org/10.1002/pri.417.
14. Swinkels RA, van Peppen RP, Wittink H, Custers JW, Beurskens AJ. Current use and barriers and facilitators for implementation of standardized measures in physical therapy in the Netherlands. BMC Musculoskelet Disord. 2011;12:106. https://doi.org/10.1186/1471-2474-12-106.

15. Copeland JM, Taylor WJ, Dean SG. Factors influencing the use of outcome measures for patients with low back pain: a survey of New Zealand physical therapists. Phys Ther. 2008;88(12):1492-505. https://doi.org/10.2522/ptj. 20080083.

16. Abrams D, Davidson M, Harrick J, Harcourt P, Zylinski M, Clancy J. Monitoring the change: current trends in outcome measure usage in physiotherapy. Man Ther. 2006:11:46-53. https://doi.org/10.1016/j.math.2005.02.003.

17. Yoward LS, Doherty P, Boyes C. A survey of outcome measurement of balance, walking and gait amongst physiotherapists working in neurology in the UK. Physiotherapy. 2008;94(2):125-32.

18. Chapman JR, Norvell DC, Hermsmeyer JT, Bransford RJ, DeVine J, McGirt MJ, et al. Evaluating common outcomes for measuring treatment success for chronic low back pain. Spine (Phila Pa 1976). 2011;36(21 Suppl):S54-68. https://doi.org/10.1097/BRS.0b013e31822ef74d.

19. Colquhoun $H$, Letts L, Law M, MacDermid J. Edwards: feasibility of the Canadian occupational performance measure for routine use. Br J Occup Ther. 2010;73(2):48-54. https://doi.org/10.4276/030802210X12658062793726.

20. Simmons-Mackie $N$, Threats $\Pi$, Kagan A. Outcome assessment in aphasia: a survey. J Commun Disord. 2005;38(1):1-27.

21. Huijbregts MPJ, Myers AM, Kay TM, Gavin TS. Systematic outcome measurement in clinical practice: challenges experienced by physiotherapists. Physiother Can. 2002;54(1):25-36

\section{Submit your next manuscript to BioMed Central and we will help you at every step:}

- We accept pre-submission inquiries

- Our selector tool helps you to find the most relevant journal

- We provide round the clock customer support

- Convenient online submission

- Thorough peer review

- Inclusion in PubMed and all major indexing services

- Maximum visibility for your research

Submit your manuscript at www.biomedcentral.com/submit
Biomed Central 